\title{
Upaya Peningkatan Hasil Belajar Siswa dengan Menggunakan Metode Diskusi pada Mata Pelajaran IPS Pokok Bahasan Perkembangan Teknologi di Kelas IV B SD Negeri 200118 Sadabuan Padangsidimpuan TA. 2016/2017
}

\author{
ERLAN SARI MAYATI. Z, S.Pd
}

NIP: 196509031986042006

Email : esari8685@gmail.com

\begin{abstract}
Abstrak
Tujuan penelitian ini adalahUntuk meningkatkan hasil belajar siswa dengan menggunakan metode diskusi pada pokok bahasan Perkembangan Teknologi pada siswa Kelas IV B SD Negeri 200118 Sadabuan Padangsidimpuan TA.2016/2017.

Jenis dari penelitian ini adalah penelitian tindakan kelas (PTK) pendekatan yang dilakukan adalah pendekatan kualitatif karena penelitian ini bertujuan untuk mengungkapkan kesulitankesulitan yang dialami siswa diKelas IV B SD Negeri 200118 Sadabuan Padangsidimpuan dan cara mengatasinya untuk meningkatkan hasil belajar siswa.

Subyek penelitian dalam PTK ini adalah siswa Kelas IV B SD Negeri 200118 Sadabuan Padangsidimpuan TA.2016/2017, yang berjumlah 38 orang siswa terdiri dari 20 laki-laki dan 18 perempuan. Penetapan kelas ini diambil berdasarkan hasil observasi terhadap kelas yang akan diteliti dan rujukan dengan kepala sekolah.

Hasil penelitian memaparkan bahwa sebelum melakukan tindakan, siswa diberikan pre test, hasilnya dari 38 jumlah siswa hanya 14 orang siswa $(36,84 \%)$ yang mencapai syarat ketuntasan belajar dan 24 orang siswa yang belum mencapai ketuntasan $(63,16 \%)$ dan dari pre test diperoleh nilai rata-rata kelas 57,63 mendapatkan hasil belajar yang rendah. Setelah siklus I ini, guru memberikan post test diperoleh 38 jumlah siswa bahwa 23 orang siswa $(60,53 \%)$ telah mencapai tingkat ketuntasan belajar dan 15 orag siswa $(39,47 \%)$ belum mencapai tingkat ketuntasan belajar yang diharapkan dengan nilai rata-rata kelas 73,13. Pada Siklus II diperoleh dari 38 jumlah siswa terdapat 34 orang siswa $(89,47 \%)$ telah mencapai tingkat ketuntasan belajar dan 4 orang siswa $(10,53 \%)$ belum mencapai tingkat ketuntasan belajar dan nilai rata-rata kelas 87,37.
\end{abstract}

\section{PENDAHULUAN}

Proses pendidikan merupakan satu upaya memanusiakan manusia. Dengan pendidikan cakrawala pengetahuan akan bertambah. Hal ini yang akan membentuk nilai, sikap, dan perilaku. Untuk meningkatkan kualitas pendidikan bukanlah suatu hal yang mudah dilaksanakan karena ada faktor yang mempengaruhi, misalnya: (1) pemahaman siswa dalam menguasai pokok bahasan yang diberikan, (2) guru harus memiliki pengetahuan dan keterampilan untuk mengajar seperti pendekatan atau model pembelajaran yang diberikan, dengan demikian siswa dapat diharapkan dapat meningkatkan keterlibatannya dalam kegiatan belajar mengajar dan tentunya dapat meningkatkan pemahamannya sendiri terhadap pokok bahasan, oleh karena itu pendidikan memegang peranan penting menjamin kelangsungan hidup bangsa dan negara yaitu menciptakan masyarakat yang cerdas dan pintar.

Mata Pelajaran IPS dirancang untuk mengembangkan kemampuan anak didik agar menjadi anggota masyarakat yang memiliki pengetahuan, pemahaman, dan kemampuan analisis terhadap kondisi sosial masyarakat dalam memasuki kehidupan bermasyarakat yang dinamis. Selain itu juga diharapkan mereka memiliki sikap dan karakter sebagai warga negara, dan memiliki keterampilan berpartisipasi dalam kehidupan berbangsa dan bernegara Menurut Trianto, (2010:193)“Mata pelajaran IPS bertujuan mengembangkan potensi peserta didik agar peka terhadap masalah sosial yang terjadi di 
masyarakat, memiliki sikap mental positif yang berjumlah 10 orang saja yang mendapatkan terhadap perbaikan segala ketimpangan yang nilai tuntas dalam pelajaran IPS dengan nilai rataterjadi, dan terampil mengatasi setiap masalah rata $65-70$, dan $63,16 \%$ siswa yang berjumlah yang terjadi sehari-hari baik yang menimpa 24 orang yang mengalami kesulitan dalam dirinya sendiri maupun yang menimpa kehidupan mengerjakan soal tersebut dengan nilai 20-60, masyarakat".

Penjelasan diatas maka dapat disimpulkan bahwa IPS adalah menaruh perhatian terhadap isu-isu dan masalah-masalah sosial, serta mampu membuat analisis yang kritis, selanjutnya mampu mengambil tindakan yang tepat. Hal inilah Sebagai pendidik maupun tenaga kerja pengajar, guru atau pendidik berkewajiban untuk meningkatkan hasil belajar siswanya, dengan cara menciptakan kegiatan belajar yang mampu membangun kemampuan siswa untuk memahami pelajaran sehingga tercapai hasil belajar yang optimal demi untuk mencapai tujuan pendidikan.

Guru sebagai pengajar merupakan pencipta kondisi belajar siswa yang didesain secara sengaja, sistematis dan berkesinambungan, oleh karena itu hal yang dituntut dari guru adalah bagaimana bahan pelajaran yang disampaikan guru dapat dikuasai oleh anak didik secara tuntas. Ini merupakan masalah yang cukup sulit yang dirasakan oleh guru, kesulitan itu dikarenakan anak didik bukan hanya sebagai individu, tetapi mereka juga sebagai makhluk sosial dengan latar belakang yang berlainan.

Kegiatan belajar mengajar, tidak semua siswa mampu berkonsentrasi dalam waktu yang relatif lama, terutama apabila pembelajaran yang dilakukan guru hanyalah menggunakan metode ceramah saja yang hanya menjelaskan isi materi, sehingga siswa akan menjadi kurang bergairah dalam belajar, jenuh,melamun, pasif, dan tidak bersemangat, hal tersebut dikarenakan kurangnya komunikasi dengan guru, dan kurang mengembangkan pendapat atau ide yang ada di dalam diri anak tersebut. Dan akhirnya kegiatan belajar tersebutlah yang dapat membuat anak menjadi malas belajar, dan berdampak kepada hasil belajar siswa.

Hasil observasi di SD Negeri 200118 Sadabuan Padangsidimpuan. Khususnya pada pelajaran IPS hasil belajar anak didik masih sangat rendah, hal tersebut dapat dilihat dari nilai formatif, bahwa siswa yang berjumlah 38 siswa, dimana terdiri dari 22 siswa laki-laki dan 16 siswa perempuan, mengalami kesulitan dalam menyelesaikan soal-soal yang diberikan guru, hal dimana ketuntasan nilai ujian harus mencapai 6,5 .

Menurut Roestiyah (dalam syaiful bahri djamarah 1995 : 74 ), "guru harus memiliki strategi agar anak didik dapat belajar secara efektif dan efisien, mengena pada tujuan yang diharapkan, dan salah satu langkah untuk memiliki strategi itu adalah harus menguasai teknik-teknik penyajian atau biasanya disebut metode mengajar".

Metode yang digunakan guru dalam mengajar disekolah antara lain, meliputi: metode ceramah, metode tanya jawab, metode diskusi, metode kerja kelompok, metode simulasi, metode demonstrasi, metode pemecahan masalah, metode penugasan, metode proyek, metode pameran, dan beberapa macam lagi.

Penjelasan diatas maka dapat disimpulkan bahwa metode diskusi bersifat bertukar pengalaman untuk menentukan keputusan tertentu secara bersama-sama.Oleh karena itulah di dalam permasalahan diatas maka saya sebagai peneliti melakukan penelitian yang berjudul " Upaya Peningkatan Hasil Belajar Siswa dengan Menggunakan Metode Diskusi pada Mata Pelajaran IPS Pokok Bahasan Perkembangan Teknologi di Kelas IV B SD Negeri 200118 Sadabuan Padangsidimpuan TA.2016/2017”.

\section{METODE PENELITIAN}

Jenis dari penelitian ini adalah penelitian tindakan kelas (PTK) pendekatan yang dilakukan adalah pendekatan kuantitatif karena penelitian ini bertujuan untuk mengungkapkan kesulitankesulitan yang dialami siswa di Kelas IV B SDN 200118 Sadabuan Padangsidimpuan dan cara mengatasinya untuk meningkatkan hasil belajar siswa.

\section{HASIL PENELITIAN DAN PEMBAHASAN}

Laporan umum dalam penelitian tindakan kelas ini disajikan dengan menampilkan analisis kualitatif dan kuantitatif. Dimana analisis kualitatif data mengacu pada konsep teori yang ada, analisis tersebut dilakukan untuk tersebut dapat dilihat bahwa hanya $31,25 \%$ siswa memperoleh gambaran umum dan menyeluruh 
dari objek penelitian atau situasi sosial, pertanyaan-pertanyaan, informasi, peristiwaperistiwa yang terjadi dalam pelaksanaan tindakan, hasil observasi, refleksi dan para aktor sekolah serta evaluasi, sedangkan analisis kuantitatif yaitu analisis persentase siswa secara individual maupun klasikal dengan tujuan mengetahui peningkatan hasil belajar siswa dengan menggunakan metode diskusi pada pokok bahasan Perkembangan Teknologi di Kelas IV B SD Negeri 200118 Sadabuan Padangsidimpuan TA.2016/2017.

Proses belajar mengajar bertujuan untuk meningkatkan hasil belajar siswa. Oleh karenanya dapat dikatakan salah satu faktor penting yang menentukan kegiatan belajar mengajar adalah metode yang digunakan guru dalam proses pembelajaran, sebelum diterapkannya metode diksusi, terlebih dahulu peneliti mewancarai guru Kelas IV B SD Negeri 200118 Sadabuan Padangsidimpuan, dengan tujuan untuk mengetahui hasil belajar siswa terhadap mata pelajaran IPS .

Ternyata dari hasil observasi yang dilakukan, diketahui bahwa hasil belajar siswa pada mata pelajaran IPS masih tergolong rendah dan dibawah ketuntasan belajar, untuk mengetahui lebih jauh kemudian peneliti memberikan tes awal kepada siswa dengan maksud untuk mengetahui hasil belajar siswa sebelum dilakukannya tindakan pada siklus I.

Berdasarkan test awal yang diberikan peneliti kepada siswa Kelas IV B SDN 200118 Sadabuan Padangsidimpuan berjumlah 38 orang siswa, maka dapat diketahui hasil belajar siswa yang dapat dilihat dari tabel di bawah ini.

Tabel 1

Hasil Belajar Siswa Pada Pre Tes

\begin{tabular}{|c|l|c|c|c|}
\hline \multirow{2}{*}{ No } & \multirow{2}{*}{$\begin{array}{c}\text { Nama } \\
\text { Responden }\end{array}$} & $\begin{array}{c}\text { Ni } \\
\text { lai }\end{array}$ & \multicolumn{2}{|c|}{ KRITERIA } \\
\cline { 3 - 5 } & & & $\begin{array}{c}\text { Tunta } \\
\text { s }\end{array}$ & $\begin{array}{c}\text { Belum } \\
\text { Tuntas }\end{array}$ \\
\hline 1 & Bayu Septian & 80 & Tuntas & \\
\hline 2 & Dini Maryani & 60 & & $\begin{array}{c}\text { Belum } \\
\text { tuntas }\end{array}$ \\
\hline 3 & Divasha Umesh & 40 & & Belum \\
\hline
\end{tabular}

\begin{tabular}{|c|c|c|c|c|}
\hline & & & & tuntas \\
\hline 4 & $\begin{array}{l}\text { Elfimeisyah } \\
\text { Ritonga }\end{array}$ & 80 & Tuntas & \\
\hline 5 & $\begin{array}{l}\text { Fahri } \quad \text { Riski } \\
\text { Almar }\end{array}$ & 60 & & $\begin{array}{l}\text { Belum } \\
\text { tuntas }\end{array}$ \\
\hline 6 & $\begin{array}{l}\text { Farhan } \\
\text { Almar }\end{array}$ & 40 & & $\begin{array}{l}\text { Belum } \\
\text { tuntas }\end{array}$ \\
\hline 7 & Faiq Naufal & 40 & & $\begin{array}{l}\text { Belum } \\
\text { tuntas }\end{array}$ \\
\hline 8 & Fadli Hidayat & 80 & Tuntas & \\
\hline 9 & $\begin{array}{l}\text { Handyika } \\
\text { Martua Tanjung }\end{array}$ & 40 & & $\begin{array}{l}\text { Belum } \\
\text { tuntas }\end{array}$ \\
\hline 10 & Intan Meilani & 40 & & $\begin{array}{l}\text { Belum } \\
\text { tuntas }\end{array}$ \\
\hline 11 & Karisa Oktavia & 80 & Tuntas & \\
\hline 12 & $\begin{array}{l}\text { Khoirunnisa } \\
\text { Putri }\end{array}$ & 80 & Tuntas & \\
\hline 13 & $\begin{array}{l}\text { Muhammad } \\
\text { Azhari }\end{array}$ & 40 & & $\begin{array}{l}\text { Belum } \\
\text { tuntas }\end{array}$ \\
\hline 14 & $\begin{array}{l}\text { Muhammad } \\
\text { Fadhil Harahap }\end{array}$ & 80 & Tuntas & \\
\hline 15 & $\begin{array}{l}\text { Muhammad } \\
\text { Rivaldo }\end{array}$ & 60 & & $\begin{array}{l}\text { Belum } \\
\text { tuntas }\end{array}$ \\
\hline 16 & $\begin{array}{l}\text { Muhammad } \\
\text { Zafar Mustaza }\end{array}$ & 80 & Tuntas & \\
\hline 17 & $\begin{array}{l}\text { Mutiara Akhyar } \\
\text { Pulungan }\end{array}$ & 60 & & $\begin{array}{l}\text { Belum } \\
\text { tuntas }\end{array}$ \\
\hline 18 & $\begin{array}{l}\text { Muhammad } \\
\text { Fazri Nasution }\end{array}$ & 20 & & $\begin{array}{l}\text { Belum } \\
\text { tuntas }\end{array}$ \\
\hline 19 & Nova & 40 & & $\begin{array}{l}\text { Belum } \\
\text { tuntas }\end{array}$ \\
\hline 20 & Nurindah Safitri & 80 & Tuntas & \\
\hline 21 & Nurasiah Pane & 40 & & $\begin{array}{l}\text { Belum } \\
\text { tuntas }\end{array}$ \\
\hline 22 & $\begin{array}{l}\text { Raisah Ganza } \\
\text { Rizki Siregar }\end{array}$ & 40 & & $\begin{array}{l}\text { Belum } \\
\text { tuntas }\end{array}$ \\
\hline 23 & $\begin{array}{ll}\text { Refnita } & \text { Sari } \\
\text { Harahap } & \\
\end{array}$ & 80 & Tuntas & \\
\hline 24 & $\begin{array}{l}\text { Rifki } \quad \text { Fadil } \\
\text { Siregar }\end{array}$ & 60 & & $\begin{array}{l}\text { Belum } \\
\text { tuntas }\end{array}$ \\
\hline 25 & Riki Saputra & 80 & Tuntas & \\
\hline 26 & $\begin{array}{ll}\text { Riyan } & \text { Nauli } \\
\text { Siregar } & \\
\end{array}$ & 80 & Tuntas & \\
\hline 27 & Rizki Laura & 40 & & $\begin{array}{l}\text { BelumTun } \\
\text { tas }\end{array}$ \\
\hline
\end{tabular}


Volume 3 Nomor 1, Halaman 1-81, Januari--Juni 2018

RISTEKDIK | Jurnal Bimbingan dan Konseling

P-ISSN: 2527-4244, E-ISSN : 2541-206X

\begin{tabular}{|c|c|c|c|c|}
\hline 28 & $\begin{array}{l}\text { Rizky } \\
\text { Rahmadani }\end{array}$ & 60 & & $\begin{array}{l}\text { BelumTun } \\
\text { tas }\end{array}$ \\
\hline 29 & $\begin{array}{l}\text { Saira } \\
\text { Rahmadhani }\end{array}$ & 40 & & $\begin{array}{l}\text { BelumTun } \\
\text { tas }\end{array}$ \\
\hline 30 & $\begin{array}{l}\text { Salwa } \\
\text { Meizaskiya }\end{array}$ & 80 & Tuntas & \\
\hline 31 & $\begin{array}{l}\text { Seri Hartati } \\
\text { Hasibuan }\end{array}$ & 40 & & \\
\hline 32 & $\begin{array}{l}\text { Shiva Almira } \\
\text { Ramadhani }\end{array}$ & 60 & & $\begin{array}{l}\text { BelumTun } \\
\text { tas }\end{array}$ \\
\hline 33 & $\begin{array}{l}\text { Siti Aminah } \\
\text { Siagian }\end{array}$ & 80 & Tuntas & \\
\hline 34 & Tio Bintang & 40 & & $\begin{array}{l}\text { Belum } \\
\text { tuntas }\end{array}$ \\
\hline 35 & $\begin{array}{ll}\text { Yumna } & \text { Saro } \\
\text { Harahap } & \end{array}$ & 60 & & $\begin{array}{l}\text { Belum } \\
\text { tuntas }\end{array}$ \\
\hline 36 & $\begin{array}{l}\text { Ummi Kalsum } \\
\text { Harahap }\end{array}$ & 40 & & $\begin{array}{l}\text { BelumTun } \\
\text { tas }\end{array}$ \\
\hline 37 & Ema Rosalina & 80 & Tuntas & \\
\hline 38 & $\begin{array}{l}\text { Amelia Sari } \\
\text { Dewi }\end{array}$ & 40 & & $\begin{array}{l}\text { BelumTun } \\
\text { tas }\end{array}$ \\
\hline & Jumlah & $\begin{array}{l}21 \\
90\end{array}$ & & \\
\hline & Rata-rata & $\begin{array}{l}57 \\
6 \\
3\end{array}$ & & \\
\hline & Ketuntasan & $\begin{array}{c}36 \\
, 8 \\
4\end{array}$ & & \\
\hline & Belum Tuntas & $\begin{array}{c}63 \\
, 1 \\
6\end{array}$ & & \\
\hline
\end{tabular}

\begin{tabular}{|c|c|c|c|}
\hline 80 & 14 & $36.84 \%$ & Tuntas \\
\hline 100 & - & - & - \\
\hline \multicolumn{2}{|c|}{ Jumlah nilai } & \multicolumn{2}{|r|}{2190} \\
\hline \multicolumn{2}{|c|}{ Jumlah siswa } & \multicolumn{2}{|r|}{38} \\
\hline \multicolumn{2}{|c|}{ Rata-rata nilai } & \multicolumn{2}{|r|}{57,63} \\
\hline
\end{tabular}

Berdasarkan tabel di atas menunjukkan bahwa penguasaan materi perkembangan teknologi masih rendah. Terlihat dari nilai-nilai rata rata kelas hanya mencapai 57,63 , dari 38 jumlah siswa terdapat 24 orang $(63,16 \%)$ yang mendapat hasil belajar yang belum tuntas, sedangkan hasil belajar siswa yang mencapai syarat ketuntasan sebanyak 14 orang siswa $(36,84 \%)$.

Hasil belajar secara klasikal adalah :

$\mathrm{P}=\frac{f}{n} \mathrm{x} 100 \%$

$\mathrm{P}=\frac{14}{38} \mathrm{x} 100 \%=36,84 \%$

Hasil belajar siswa pada pre tes juga dapat dilihat melalui diagram di bawah ini :

Gambar 2

Diagram hasil belajar siswa pada pre test

Tabel 2

Distribusi tingkat hasil belajar pre test

\begin{tabular}{|c|c|c|c|}
\hline Nilai & F & $\begin{array}{c}\text { Persentase } \\
\%\end{array}$ & Kriteria \\
\hline 20 & 1 & $2.63 \%$ & $\begin{array}{c}\text { Belum } \\
\text { tuntas }\end{array}$ \\
\hline 40 & 15 & $39.47 \%$ & $\begin{array}{c}\text { Belum } \\
\text { tuntas }\end{array}$ \\
\hline 60 & 8 & $21.05 \%$ & $\begin{array}{c}\text { Belum } \\
\text { tuntas }\end{array}$ \\
\hline
\end{tabular}

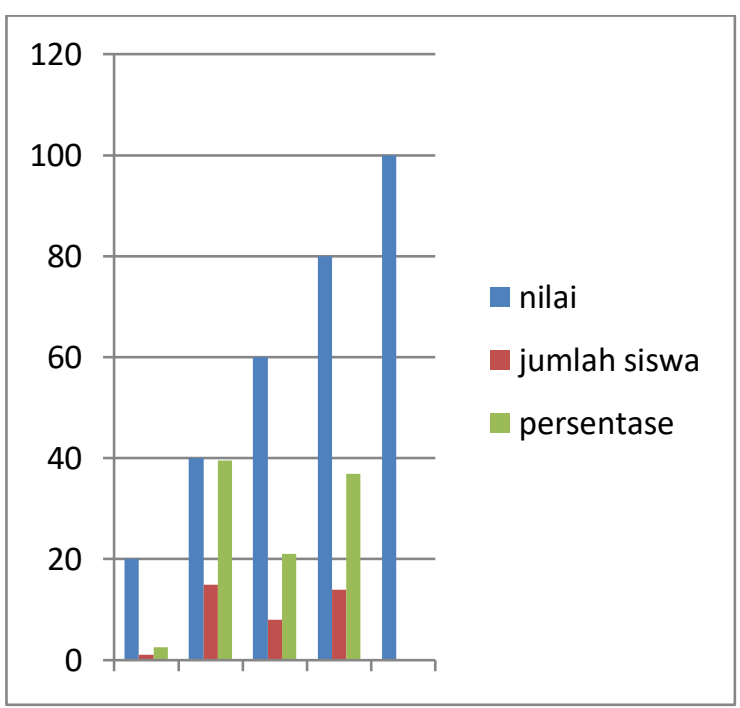


Volume 3 Nomor 1, Halaman 1-81, Januari--Juni 2018

RISTEKDIK | Jurnal Bimbingan dan Konseling

P-ISSN: 2527-4244, E-ISSN : 2541-206X

KESIMPULAN

Berdasarkan hasil penelitian yang disajikan pada bab IV dapat diambil kesimpulan yaitu:

1. Sebelum melakukan tindakan, siswa diberikan pre test, hasilnya dari 38 jumlah siswa hanya 14 orang siswa $(36,84 \%)$ yang mencapai syarat ketuntasan belajar dan 24 orang siswa yang tidak memenuhi syarat ketuntasan $(63,16 \%)$ dan dari pre test diperoleh nilai rata-rata kelas 57,63 mendapatkan hasil belajar yang rendah.

2. Setelah siklus I ini, guru memberikan post test diperoleh 38 jumlah siswa bahwa 23 orang siswa $(60,53 \%)$ telah mencapai tingkat ketuntasan belajar dan 15 orag siswa $(39,47 \%)$ belum mencapai tingkat ketuntasan belajar yang diharapkan dengan nilai rata-rata kelas 75,26.

3. Pada Siklus II diperoleh dari 38 jumlah siswa terdapat 34 orang siswa $(89,47 \%)$ telah mencapai tingkat ketuntasan belajar dan 4 orang siswa $(10,53 \%)$ belum mencapai tingkat ketuntasan belajar dan nilai rata-rata kelas 87,37 .

\section{DAFTAR PUSTAKA}

Abdurrahman, Mulyono. 2009. Pendidikan Bagi Anak berkesulitan belajar. Jakarta: Rineka cipta

Arikunto, Suharsimi.2008. Dasar-dasar evaluasi pendidikan.jakarta: PT. Bumi aksara

Aqib, Zainal. 2006. Penelitian Tindakan Kelas. Bandung: Yrama Widya.

Dewi, Rosmala.2009. Penelitian Tindakan Kelas. Medan: CV Dharma

Djamarah, Bahri, Syaiful. 1995. Strategi Belajar Mengajar. Jakarta: Rineka Cipta

. 2008. Psikologi Belajar. Jakarta: Rineka Cipta Sanjaya, wina. 2008. Strategi pembelajaran Berorientasi Standar Proses pendidikan. Jakarta: kencana

Sudjana, Nana. 2009. Penilaian Hasil Proses Belajar Mengajar. Bandung: PT. Remaja Rosdakarya
Slameto. 2002. Belajar dan Fakto-faktor Yang Mempengaruhi.Jakarta: Rineka Cipta

Trianto. 2010. Model Pembelajaran terpadu. Jakarta: Bumi Aksara

Umar, Arsyad. 2004. Pengetahuan Sosial. Jakarta

: Erlangga

http://edukasi.kompasiana.com/2011/07/09/pener apan-metode-diskusi-dalampembelajaran-di-sd/ 